International Journal of Aesthetic Medicine and Health
(DOI:10.28933/IJAMH)

\title{
Parameters used in metabolic syndrome diagnosis
}

\author{
Carvalho E.E.S.L.L1, Souza P.C2, Martins E.V.S3, Silva B.M4, Cavalcanti J.F.G5, Almeida \\ Júnior A.S.A6
}

\section{1,2,3,4,5Estudantes do Curso de Biomedicina - UNINASSAU; 6Docente - UNINASSAU.}

\begin{abstract}
Introduction: Metabolic Syndrome (MS) is a complex disorder represented by a set of cardiovascular risk factors that are directly related to the patient's eating style and physical activity, and has long been associated with insulin resistance. All proposed diagnostic criteria for the Metabolic Syndrome (MS) take into account abdominal obesity. Several guidelines to define SM have been proposed over the years, the most accepted ones currently being the WHO and NCEP. Objective: To describe the laboratory parameters used to determine the Metabolic Syndrome (MS). Methodology: The present work consists of a literature review, with articles extracted from the electronic data bases Scielo, Pubmed and Lilacs, where only articles published between 2012 and 2017 were accepted. Results and discussion: The diagnosis of MS occurs when three of the five required criteria are present: large amounts of abdominal fat (men with waist measuring more than $102 \mathrm{~cm}$ and women over $88 \mathrm{~cm}$ ); low HDL (men below $40 \mathrm{mg}$ $/ \mathrm{dl}$ and in women below $50 \mathrm{mg} / \mathrm{dl}$ ); high triglycerides $(150 \mathrm{mg}$ / dl or higher, for both men and women); high blood pressure $(135 / 85 \mathrm{mmHg}$ or higher or if you are using any medicine to reduce pressure); (100mg / dl or higher for both sexes). Some additional metabolic criteria may be: atherogenic dyslipidemia, insulin resistance, prothrombotic state, among others. Conclusion: The diagnosis of the Metabolic Syndrome takes into account the clinical characteristics and laboratory data which provide an accurate assessment of the physiological state of the patient. However, it is necessary to establish new parameters more specific for its diagnosis, since some of these already existent, such as triglycerides, can affect others in the case of LDL-c, causing a misdiagnosis.
\end{abstract}

Keywords: LDL; Obesity; Metabolic syndrome; Triglycerides
*Correspondence to Author:

Carvalho E.E.S.L.L

Estudantes do Curso de Biomedici-

na - UNINASSAU

How to cite this article:

Carvalho E.E.S.L.L, Souza P.C, Martins E.V.S, Silva B.M, Cavalcanti J.F.G, Almeida Júnior A.S.A. Parameters used in metabolic syndrome diagnosis.International Journal of Aesthetic Medicine and Health, 2018, 1:4

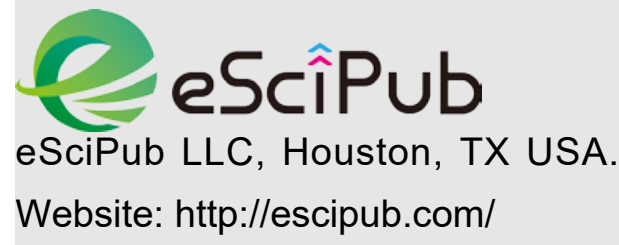

Website: http://escipub.com/ 